\title{
Strengthening of masonry and concrete structures working in elevated temperatures and mining tremors area
}

\author{
Bogusław Zając ${ }^{1}$, Arkadiusz Kwiecieńn ${ }^{2,}$, Matija Gams ${ }^{2}$ and Tadeusz Tatara ${ }^{1}$ \\ ${ }^{1}$ Cracow University of Technology, Faculty of Civil Engineering, Cracow, Poland \\ ${ }^{2}$ University of Ljubljana, Faculty of Civil and Geodetic Engineering, Ljubljana, Slovenia
}

\begin{abstract}
In this paper, comparison of behaviour of composite strengthening bonded to concrete and masonry substrate are presented. Specimens are tested in single lap shear tests under constant load and action of elevated temperatures. Obtained results showed that tested stiff epoxy adhesives are vulnerable to elevated temperatures, changing strain distribution, whereas the tested flexible polyurethane adhesive works stable in the whole tested temperature range. The carried out analysis concerns cracked industrial chimneys working in mining areas, which are strengthened with composite materials and carry thermal and dynamic loads, and can be responsible for the composite strengthening detachment.
\end{abstract}

Keywords: elevated temperatures, industrial chimneys, stiff and flexible adhesives, glass transition temperature, mining tremors

\section{Introduction}

Mining areas are one of the oldest industrial territories in Poland where masonry and structures are present and undergo there various degradation influences. Dynamic excitations made by mining tremors and uneven settlements made by ground surface deformations cause damages to structures, which require repair or strengthening. These deformations are induced by inertial forces (caused by mining tremors) or by foundation movement (caused by settlement or sliding). To protect the cracked structures against damage external intervention methods are applied. Using of composite materials in strengthening of cracked masonry and concrete structures is popular, mainly in seismic areas, where damaged structures are endangered by large deformations.

In the last decade, various composite fibres (carbon, glass, basalt, aramid and steel) and various matrices (epoxy, mineral, polyurethane) were proposed as composite strengthening of masonry and concrete structures. They were tested mainly in quasi-static tests in laboratories and in situ under normal thermal conditions (room temperature), manifesting

\footnotetext{
* Corresponding author: $\underline{\text { akwiecie@pk.edu.pl }}$
} 
their efficiency in all these tests. More realistic behaviour of composite-to-substrate strengthening was analyzed by cyclic tests with the mentioned above matrices and glass net. These tests showed that stiff epoxy and mineral matrices cause low effectiveness to composite-to-substrate strengthening, when large cyclic deformations are applied to a brittle (masonry) structure. On the other hand, flexible polyurethane matrix in composite strengthening is able to withstand large cyclic deformations and dissipate large amount of deformation energy, as well as to improve the strength and ductility of the strengthened structure.

Durability aspects of composite strengthening started to be considered in the last years [1]. Because of high popularity of epoxy matrices, vulnerability of them to elevated temperatures is one of main interest. Epoxies are characterized by glass transition temperature $\left(T_{g}\right)$ in which their properties (stiffness and strength) are rapidly degraded. Most of epoxies manifest their $T_{g}$ in environmental and exploitation range of elevated temperatures $\left(40-80^{\circ} \mathrm{C}\right)$, easily reached at surfaces exposed to the sun radiation or heated by industrial devices or processes. Combination of elevated temperature and accidental loads acting on composite-to-substrate strengthening is possible in industrial structures allocated in seismic or mining tremor areas $[2,3]$, thus this topic is discussed in this paper.

\section{Strengthening of masonry and concrete chimneys}

Industrial chimneys are the structures undergoing external and thermal loads. They are popular in industrial areas threatened by mining tremors. The masonry and concrete chimneys undergo damages in form of cracks and thus have to be strengthened when are overloaded by various loads. One of strengthening method is using of composite materials bonded externally to the chimney surface, which have to withstand exploitation and environmental loads $[2,3]$.

\subsection{Loads acting on masonry and concrete chimneys}

Chimneys are designed for gravity loads and wind loads, which include also dynamic component. The main exploitation load present in chimneys is thermal load caused by industrial gases of high temperature [3]. If a chimney has degraded a thermal isolation, elevated temperatures can be easily reached at its outer structure surface. These temperatures can be also changed by industrial devices working in surrounding or the sun radiation (acting differently in summer and winter seasons). Detection of changes in temperature distribution along the chimney height can be realized using thermography. Complex character of various thermal loads influencing the outer chimney surface can be calculated using numerical models [3], which results indicate that elevated temperature over $80^{\circ} \mathrm{C}$ is possible to be present, even if codes limit it to $70^{\circ} \mathrm{C}$ [4].

Additional dynamic loads have to be considered in seismic or mining areas, where kinematic excitation generates inertial forces on chimney structures [2]. According to the structure location, this load can have unique or cyclic character. Chimneys work often in aggressive environments, caused mainly by exhausted industrial gases, which induce corrosion of structural materials, weakening the structural resistance to loads.

\subsection{Repair and strengthening methods for damaged chimneys}

Combination of mentioned above load factors cause damages to masonry and concrete chimneys in form of cracks or spalling. They reduce structural stiffness of chimneys thus have to be repaired or strengthened. Classically using repair and strengthening methods are 
listed and described in the standard EN 1504 [5], as well as in many publications [6, 7]. They are based on using materials of high strength and stiffness, as polymer modified concrete or epoxy resins [7]. The last one material is popular as an adhesive in bonding of composite strengthening to chimneys [8].

Stiff and high strength epoxy adhesives bonding composite strengthening generate stress concentrations when deformation of the structure occurs. In the case of weak substrates (masonry chimneys or chimneys made of weak and degraded concrete), this stress concentration is responsible for detachment of composite strengthening from the substrate. Such mechanism of failure was observed in masonry walls tested under cyclic loads in laboratory temperature (Fig. 1a) [9], where no improvement of structural behaviour was detected because of failure of composite material bonded on stiff epoxy resin (Fig. 1b).

On the other hand, application of composite strengthening using flexible adhesive provided significant increase in strength and ductile behaviour of the strengthened structure and no detachment was observed. It should be noted that the composite strengthening using flexible adhesive was applied as emergency on cracked masonry surface. The strengthening was able not only increasing the ability of carrying load and dissipating energy (what is important in seismic and mining areas), but also changing crack pattern for more save. This observation was done using Digital Image Correlation method (DIC). The crack pattern of the reference wall just before failure indicates clearly disintegration of the tested structure (Fig. 2a, d). The wall damaged up to reasonable crack width (of the same character as the reference - Fig. 2b, e) was strengthened with a composite glass net bonded on the polyurethane adhesive (Fig. 2c) and tested again after 23 hours up to failure (Fig. 1c). The crack pattern just before failure (Fig. 2f), hidden under the strengthening but visible in DIC, showed that damage area is condensed in the middle of the wall but the boundaries of it are protected against crack propagation and disintegration. Even when the wall splits into two wallets in the ultimate state, the strengthening with flexible adhesive keeps all fragments of the wall together. This system was proposed as emergency repair in mining areas [10].
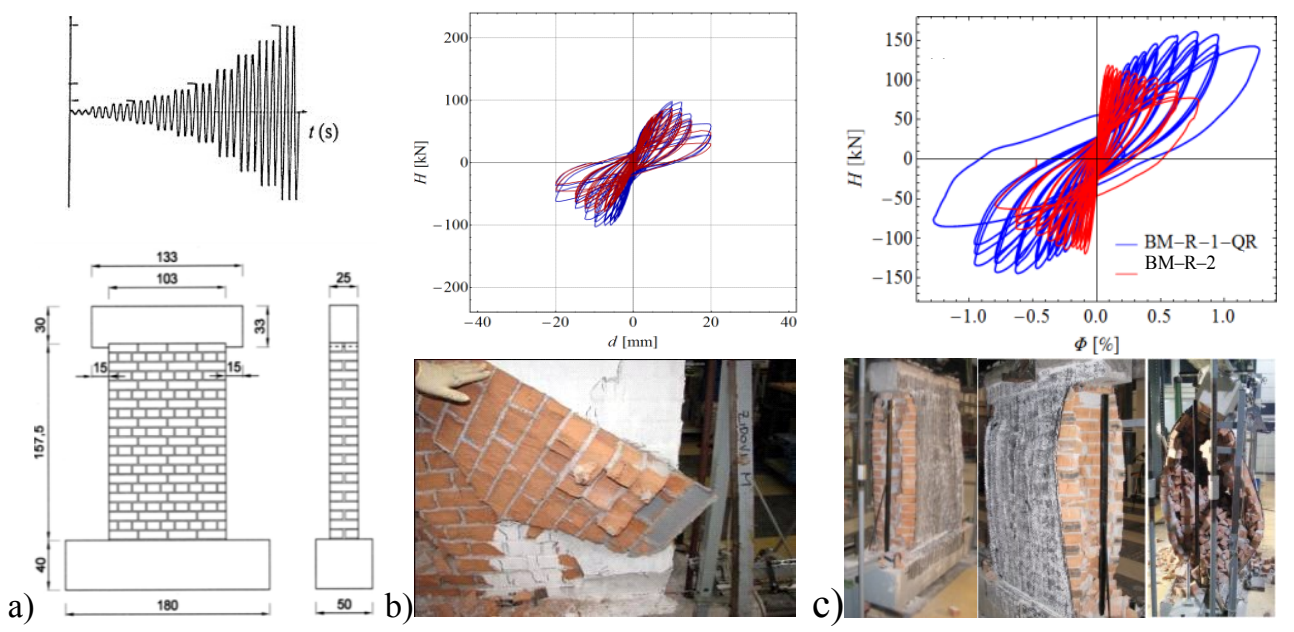

Fig. 1. Comparison of strengthening effectiveness using stiff (epoxy) and flexible (polyurethane) adhesives: scheme of the masonry wall tested in cyclic shear test (a), comparison of hysteresis loops obtained for the reference (red) and strengthened (blue) walls with failure modes: epoxy adhesive (b) and polyurethane adhesive (c) - after [9]. 
a)
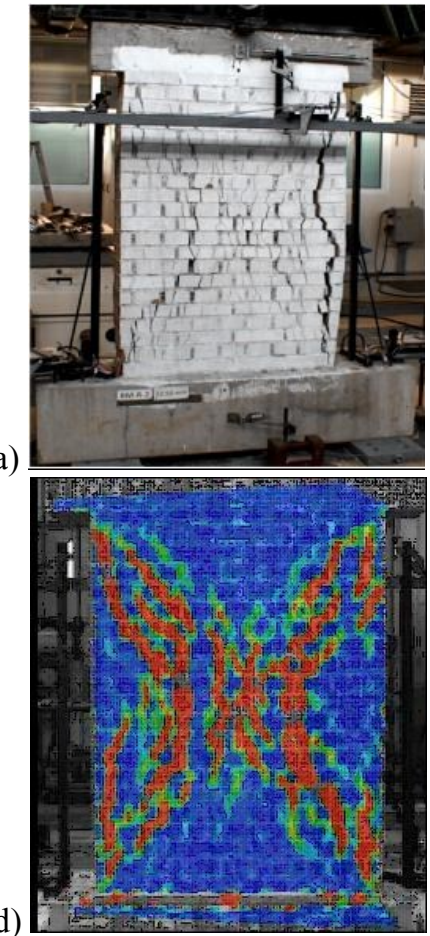

b)

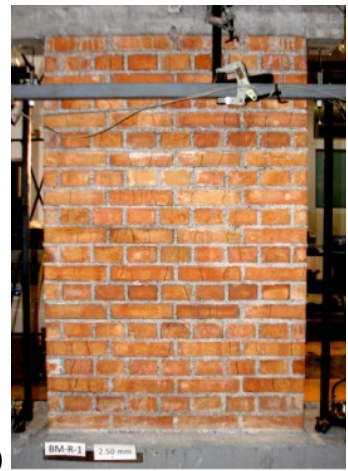

e)

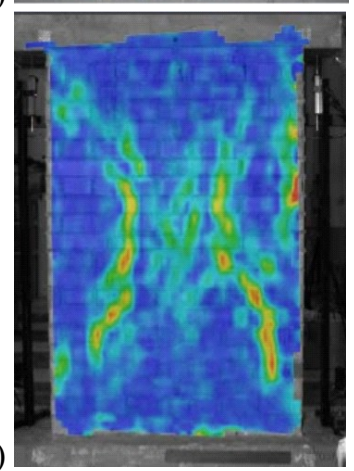

c)

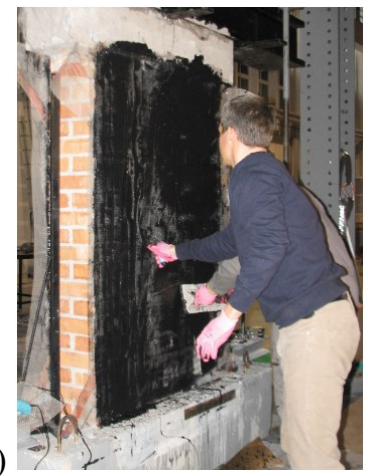

f)

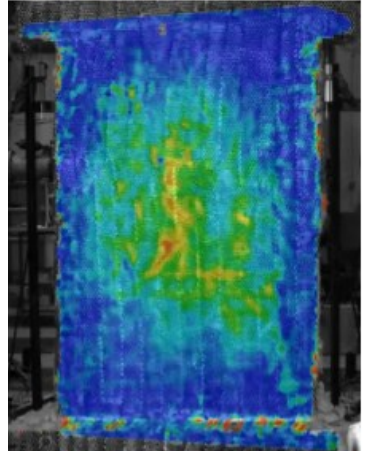

Fig. 2. Crack patterns of not strengthened and strengthened walls: reference wall just before failure (a), cracked wall just before flexible strengthening (b), wall with composite strengthening bonded on flexible adhesive (c) - after [9].

\section{Influence of elevated temperature on composite strengthening}

Elevated temperature influence significantly mechanical properties (Young modulus) of stiff epoxy adhesives ( $\mathrm{S} 30$ and $\mathrm{S} 330$ ) when their $T g$ is reached in $40-60^{\circ} \mathrm{C}-\mathrm{Fig}$. 3a. On the other hand, flexible polyurethane adhesive (PS) is stable in the whole analysed temperature.

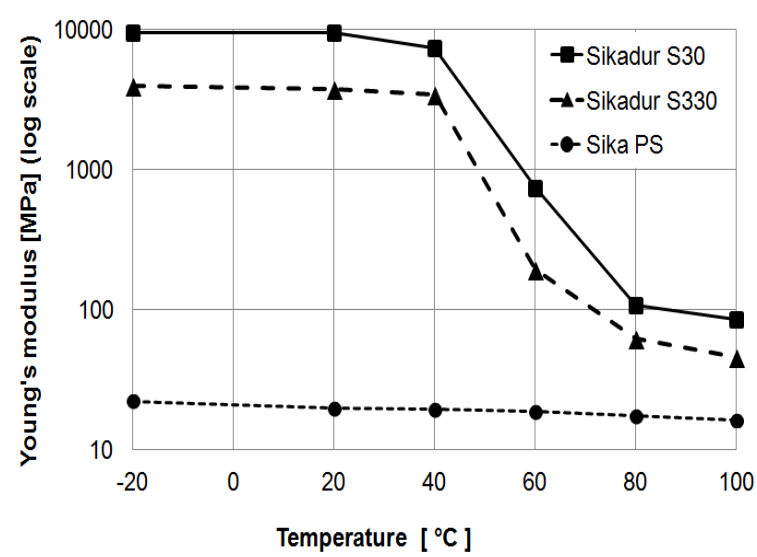

a)
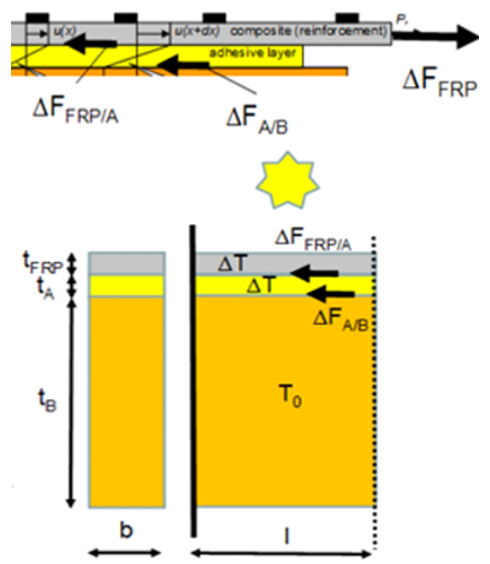

b)

Fig. 3. Change of mechanical properties of adhesives in temperature (a), scheme of shear forces generated by thermal loads in composite-to-substrate strengthening (b) [11]. 
Stable behaviour of adhesives in exploitation temperature range is important because of design requirements of predictable and stable mechanical properties of structural materials carrying loads. This is the base for calculations of composite strengthening systems. When temperature influences significantly material properties, changing initial Young modulus (Fig. 3a) and also internal shear forces (Fig. 3b) and stress distribution along the bond varies. It can cause loss of load carrying ability and thus danger of chimney failure.

Laboratory tests were carried out, to check influence of temperature change on stress distribution in the strengthening system. Specimens of single lap shear tests (Fig. 4) with constant load of $F=5 \mathrm{kN}$ applied on composite strengthening, at which surface strain gauges (T0, T1, T2, T3) were controlling strain (stress) changes, were subjected to 4 levels of temperatures $\left(20,40,60\right.$ and $\left.80^{\circ} \mathrm{C}\right)$. As substrate concrete $(\mathrm{C})$ and brick (B) elements were applied. Carbon (CFRP) laminate (SikaCarboDur S512) was bonded using two stiff epoxy resin (S30 and S330) and one flexible polyurethane (PS) adhesives. Initial Young module (in room temperature) of materials using in strengthening systems tested in laboratory are presented in Table 1. The initial Young modules of tested materials were changed with temperature changing only in the case of epoxy resins (Fig. 3a).

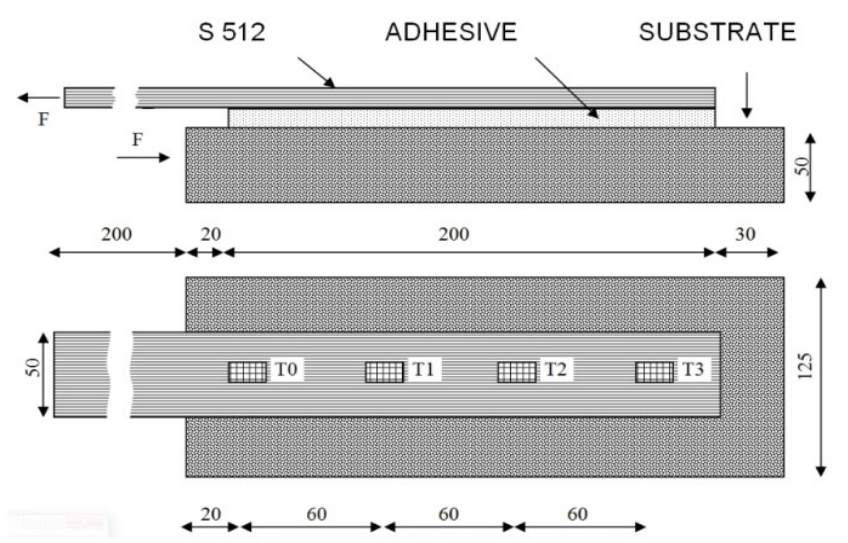

Fig. 4. Setup of the single lap shear test in various temperatures, with strain gauges bonded at the composite surface [11].

Table 1. Young modulus of adhesives and substrates (in room temperature).

\begin{tabular}{|c|c|}
\hline Material & $\begin{array}{c}\text { Young modulus } \\
\mathbf{E}[\mathbf{M P a}] \text { at } \mathbf{2 0}^{\circ} \mathbf{C}\end{array}$ \\
\hline SikaCarboDur S512 & 165000 \\
\hline Sikadur-30 & 12500 \\
\hline Sikadur-330 & 4500 \\
\hline Polyurethane PS & 16 \\
\hline Brick & 15000 \\
\hline Concrete C30/37 & 29000 \\
\hline
\end{tabular}


Results of the carried out tests described in details in [11] confirmed that influence of $\mathrm{Tg}$ on behaviour of epoxy adhesives is significant in case of their properties and stress distribution in composite-to-substrate strengthening systems. When the composite strengthening is loaded, strain (stress) distribution is observed. The constant value of strain at the CFRP laminate loaded end $(T 0=550 \mu \mathrm{m} / \mathrm{m})$ is obtained in room temperature $20^{\circ} \mathrm{C}$. Different strain distributions observed in Figure 5 are related to the initial tangent stiffness of the tested adhesives and testing temperature.

In the case of epoxy resins ( $\mathrm{S} 30$ and $\mathrm{S} 330$ ), strain distributions up to $40^{\circ} \mathrm{C}$ are rather stable and only small difference is observed in the brick (B) substrate (of lower stiffness). When temperature overcomes $T g$ of epoxy resins (over $40^{\circ} \mathrm{C}$ ), significant change in strain distribution is observed with activation of further part of the laminate toward the unloaded end. The gradient of those changes is bigger for the stiffer concrete (C) substrate.

This behaviour seems to be dangerous for durability of composite-to-substrate strengthening when the substrate is stiff, because cyclic changes of temperatures (exploitation and season day-night and winter-summer) can deteriorate adhesion properties or the substrate long-term strength. Such deterioration can result in global degradation of the composite-to-substrate strengthening and reduction of the strengthening system ability to transfer exploitation and accidental loads.
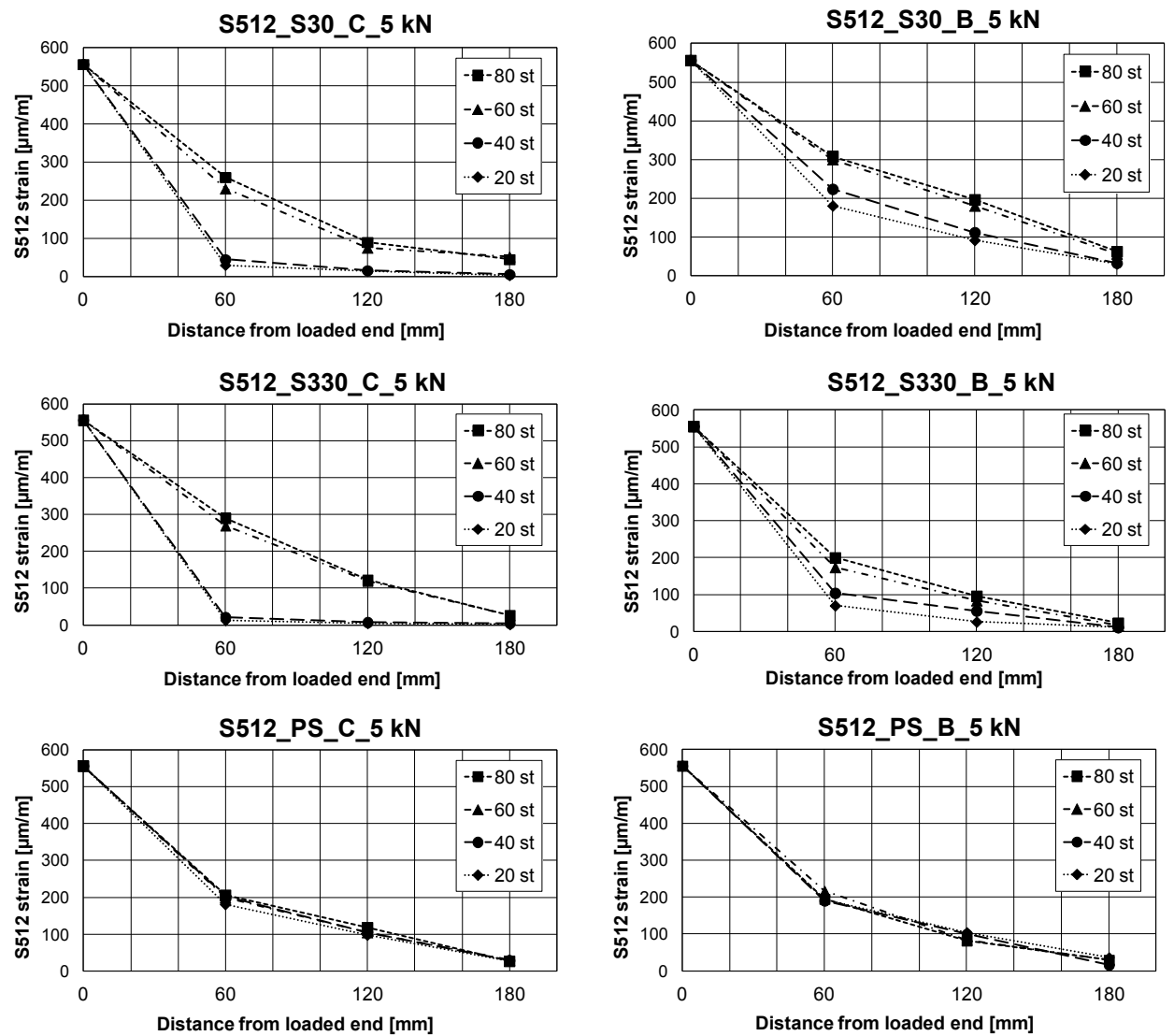

Fig. 5. Changes in strain distributions at the S512 surface, related to: the substrate stiffness of concrete (C) and brick (B), applied adhesives (S30, S330 and PS) and temperature range $40-80^{\circ} \mathrm{C}$ [11]. 
In the case of chimneys strengthened with composites bonded on epoxy resins, this process can be especially present when the substrate (concrete or masonry) is degraded by environmental and exploitation (chemical) conditions, by elevated temperature propagating by cracked or non-cracked structure and by the sun radiation. Additionally, kinematic excitations occurring cyclically (in seismic and mining areas) can accelerate this process. Because of danger of a composite strengthening detachment caused by complex cyclic action of elevated temperatures and dynamic loads (fatigue), regular control of the composite strengthening applied on industrial chimneys is recommended and failure systems should be removed to assure further safety exploitation.

In the case of flexible polyurethanes (PS), strain distributions in the whole tested temperature range $\left(20-80^{\circ} \mathrm{C}\right)$ are perfectly stable (Fig. 5). Practically, no difference is observed also between substrates of different stiffness: concrete (C) and brick (B). Polyurethane (PS) adhesive works very stable, because the tested temperature range is over its glass transition temperature $\left(T g=-40^{\circ} \mathrm{C}\right)$, thus properties of it does not change.

This behaviour seems to be safe for durability of composite-to-substrate strengthening when the substrate is stiff, because cyclic changes of temperatures (exploitation and season daynight and winter-summer) do not generate cyclic changes in stress distribution and thus do not deteriorate adhesion properties or the substrate long-term strength. This can result in safe work of the composite-to-substrate strengthening without reduction of the strengthening system ability to transfer exploitation and accidental loads.

In the case of chimneys strengthened with composites bonded on flexible polyurethanes, weak chimneys substrates are protected against damage because flexible adhesives reduce stress concentration caused by loads and deformations and are able to withstand cyclic changes of them [12]. Moreover, they are insensitive to changes of elevated temperatures and do not generate additional stresses in the composite-to-substrate strengthening systems, as it is present in the case of the strengthening systems with stiff epoxy adhesives, what is visible for temperature limits of the carried out tests (Fig. 6).
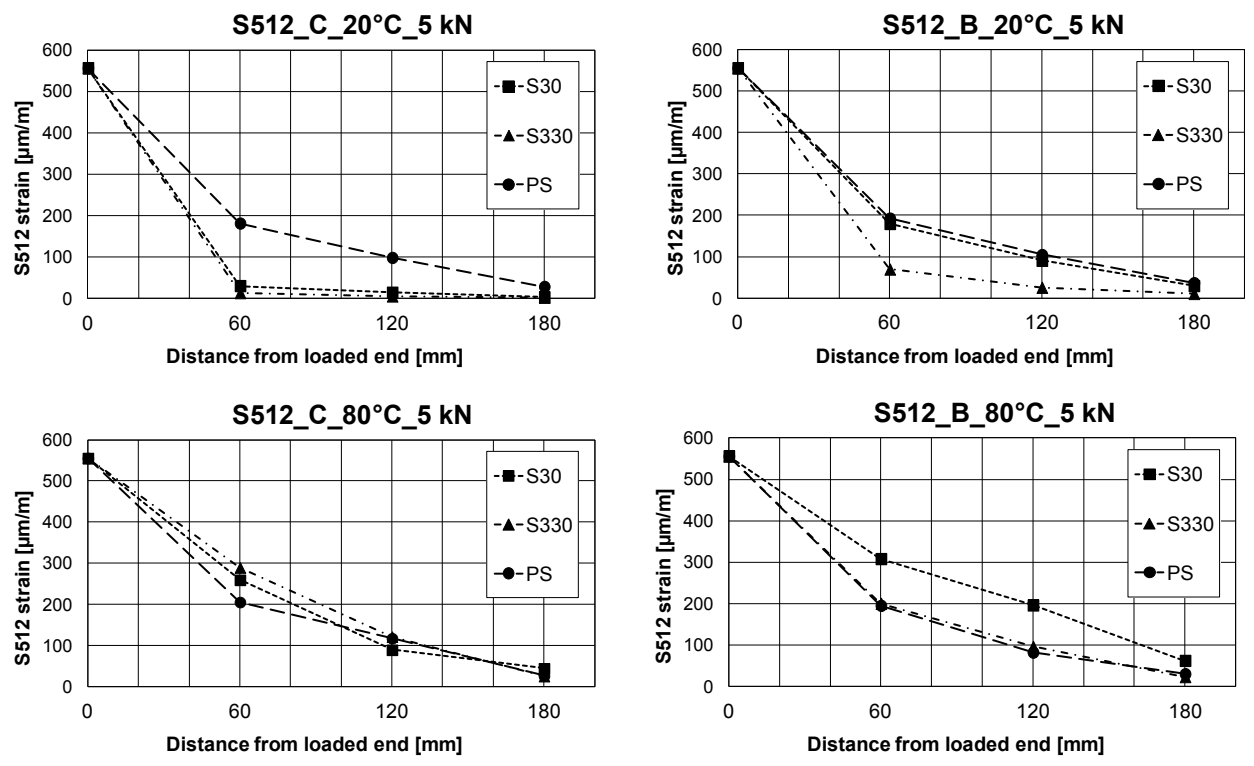

Fig. 6. Changes in strain distributions at the S512 surface, related to: the substrate stiffness of concrete (C) and brick (B), applied adhesives (S30, S330 and PS) and temperature limits $\left(20^{\circ} \mathrm{C}\right.$ and $\left.80^{\circ} \mathrm{C}\right)[11]$. 


\section{Conclusions}

Composite strengthening of industrial structures (concrete or masonry chimneys) is the method present in engineering practice. Strengthening systems using stiff epoxy adhesives (S30 and S330) are vulnerable to elevated temperatures, because of the glass transition temperature and reduction of material properties of epoxies. This influence can be dangerous for cracked industrial chimneys working in mining tremor areas, where cyclically occurring interference of thermal and dynamic loads can cause detachment of the composite strengthening. The proposed flexible polyurethane adhesive (PS) manifested their significant efficiency in laboratory tests under acting of cyclic loads and also high resistance to changing elevated temperatures, working stable without changes in stress distribution. Future tests on real scale applications of this flexible adhesive are needed.

\section{References}

1. S. De Santis, T. Stryszewska, S. Bandini, G. de Felice, Ł. Hojdys, P. Krajewski, A. Kwiecień, F. Roscini, B. Zając, Durability of steel reinforced polyurethane-to-substrate bond, Composites Part B 153, pp. 194-204 (2018)

2. T. Tatara, B. Ratajewicz, Response spectrum analysis of a RC flue-gas chimney due to the earthquakes with regard to its real technical and foundation conditions, Proc. International Conference IZIIS-50, ISBN 978-608-65185-3-0.B, (2015)

3. B. Ratajewicz, T. Tatara, Thermal analysis of reinforced concrete chimneys (in Polish) Przeglad Budowlany 6/2015 pp. 83-87 (2015)

4. M. Słowik, A. Akram, The comparison of design rules for reinforced concrete chimneys (in Polish), Budownictwo i Architektura 16(2) pp. 119-129 (2017)

5. EN 1504 : Products and systems for the protection and repair of concrete structures. Definitions, requirements, quality control and evaluation of conformity.

6. D. Morgan, Compatibility of concrete repair materials and systems. Construction and Building Materials 10 (1996) 57-67.

7. M. Sánchez, P. Faria, L. Ferrara, E. Horszczaruk, H.M. Jonkers, A. Kwiecień, J. Mosa, A. Peled, A.S. Pereira, D. Snoeck, M. Stefanidou, T. Stryszewska, B. Zając, External treatments for the preventive repair of existing constructions: A review. Construction and Building Materials 193 (2018) 435-452.

8. N. Galati, Alkhrdaji, Strengthening of RC Chimneys with FRP Composites, First Middle East Conference on Smart Monitoring, Assessment and Rehabilitation of Civil Structures, Dubai, UAE (2011)

9. M. Gams, A. Kwiecień, B. Zając, M. Tomaževič: Seismic strengthening of brick masonry walls with flexible polymer coating. Proceedings of the 9th International Masonry Conference 2014 in Guimarães, ISBN 978-972-8692-85-8, ID_1502 (2014)

10. A. Kwiecień, T. Tatara, On the possibility of repairing construction works on mining areas (in Polish). Przeglad Górniczy 6/2014, pp. 35-41.

11. B. Zając, Rigid and flexible shear adhesive connections working at elevated temperature (in Polish), Wydawnictwo Politechniki Krakowskiej, Seria Inżynieria Lądowa, Kraków, ISBN: 978-83-65-991-31-7 (2018)

12. K. Rodacki, B. Zając, A. Kwiecień, M. Tekieli, K. Furtak: The strength of wooden (timber)-glass beams combined with the polyurethane adhesive- DIC and finite element analysis. Structural analysis of historical constructions: an interdisciplinary approach. RILEM Bookseries. SAHC'2018 Cusco, Peru, pp. 323-331. 